\title{
Quarenta anos do Quarenta clics em Curitiba, de Leminski e Pires
}

\author{
Ana Luiza Fernandes ${ }^{1}$ \\ João Queiroz ${ }^{2}$
}

\section{Quarenta clics em Curitiba}

Em 2016, completaram-se 40 anos da publicação de uma das mais surpreendentes experimentações intermidiáticas da década de 1970, o fotolivro de literatura Quarenta clics em Curitiba, ${ }^{3}$ de Paulo Leminski e Jack Pires. Quase sem precedentes, a obra não aparece em qualquer antologia dedicada ao gênero "fotolivro" nem é mencionada como projeto de livro de artista (artistic book) em publicações especializadas, e segue até hoje negligenciada pela crítica e historiografia literárias. Trata-se do único exemplar de fotolivro de Leminski e sua primeira experiência como haicaísta, gênero poético extraído e adaptado de uma longa tradição literária japonesa. O escritor brasileiro é reconhecido como principal representante dessa tradição em língua portuguesa.

Considerado um complexo fenômeno intermidiático, o fotolivro é definido como uma rede "de relações entre fotografias, textos e outros materiais visuais" (Fernández, 2011, p. 16). Resultado de experimentos que fizeram "parte de importantes inovações literárias do século XX" (Silva, 2013, p. 8), os fotolivros de literatura aparecem cerca de 100 anos após a invenção do daguerreotipo, ${ }^{4}$ quando a "fotografia [dá] um golpe mortal nos velhos modos de expressão, tanto na pintura como na poesia" (Breton apud Micheli, 2008, p. 157). Porém, somente a partir das últimas décadas que os fotolivros tornaram-se alvo da atenção de pesquisadores (Fernández, 2011, p. 11; Shannon, 2010, p. 60). No Brasil, as experiências

\footnotetext{
${ }^{1}$ Doutoranda (bolsista modalidade GD - CNPq) no Departamento de Letras (Literatura, Cultura e Contemporaneidade) da Pontifícia Universidade Católica do Rio de Janeiro (PUC-Rio), Rio de Janeiro, RJ, Brasil. E-mail: analuizadagama@gmail.com

${ }^{2}$ Doutor em comunicação e semiótica e professor da Universidade Federal de Juiz de Fora (UFJF), Juiz de Fora, MG, Brasil. E-mail: queirozj@gmail.com

${ }^{3}$ Esse fotolivro teve duas edições significativas. A primeira publicação, em 1976, teve uma tiragem de 300, raros, exemplares. A segunda, publicada em 1990, teve uma tiragem de 3 mil exemplares, segundo consta na apresentação do editor Garcez Mello.

${ }^{4}$ Tecnologia que permitiu a fixação da imagem através da luz em placa metálica, apresentada à Academia de Ciências da França em 1839, por Louis Jacques Mandé Daguerre (Fonseca e Sousa, 2008, p. 149).
} 
com fotolivros de literatura ocorrem especialmente a partir da década de 1960, período que coincide com a expansão da fotografia no país. O fotolivro de Paulo Leminski e Jack Pires, de 1976, é um dos mais importantes resultados dessa expansão.

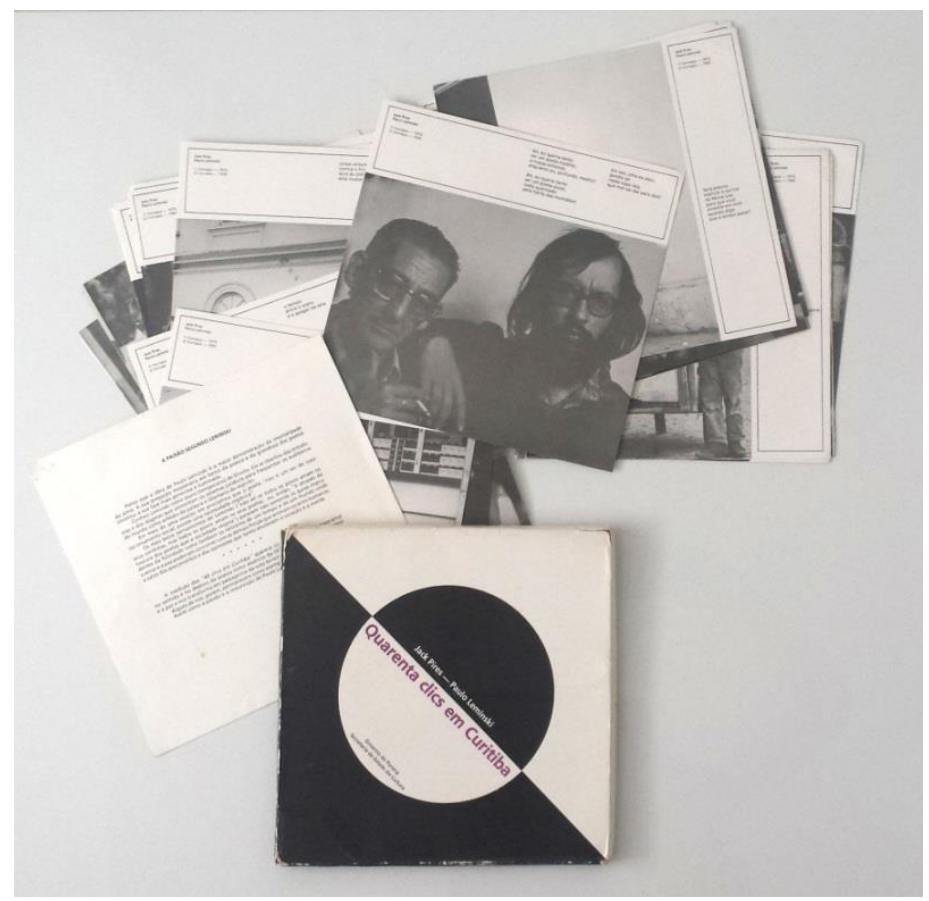

Figura 1 - Fotolivro Quarenta clics em Curitiba (Leminski e Pires, 1990).

Publicado um ano depois da prosa experimental Catatau, ${ }^{5}$ Quarenta clics em Curitiba possui um formato de livro-objeto, já que a caixa nas quais suas pranchas estão organizadas tem o formato de um livro, quadrado ou retangular, de dimensões aproximadas de $24 \mathrm{~cm} \times 24 \mathrm{~cm}$. Ele pode ser também classificado como um "livro-obra", já que o trabalho dos autores é dependente dessa estrutura de livro, e como "livro de

${ }^{5}$ Obra publicada em 1975, depois de oito anos de elaboração, é considerada uma das prosas mais criativas pós-Guimarães Rosa, e pós-Galáxias de Haroldo de Campos. "No Catatau [como nas Galáxias], a linguagem é experimentada em seus limites extremos" (Novais, 2008, p. 13). 
artista", uma vez que poeta e fotógrafo são seus autores. ${ }^{6} \mathrm{O}$ volume apresenta 40 pranchas soltas, sem numeração, nas quais 40 fotografias e 40 haicais dividem o mesmo espaço de leitura (figura 1).

A arquitetura do livro-objeto, sua estrutura solta e sem numeração, impede uma sequência orientada de leitura e cria o que pode ser interpretado como um deslocamento por ruas sem endereço, numa cidade sem centro ou hierarquia. Impedido de criar focos de atenção privilegiados e sequências narrativas, o fotolivro "recria" o ato de procrastinar pela cidade, ou o que pode ser interpretado como um deslocamento por instantes independentes, observados na cidade. Essa estrutura solta, sem vinco e numeração, intensifica ou potencializa a experiência de procrastinação pelas ruas de Curitiba.

Nosso propósito neste artigo é apresentar introdutoriamente Quarenta clics em Curitiba. Selecionamos trechos do ensaio "Click: zen e a arte da fotografia", 7 em que Leminski faz uma análise dos componentes mais fundamentais para a concepção do fotolivro. Trata-se do único ensaio em que o autor dedica-se ao Quarenta clics. Usamos, abaixo, subtítulos e trechos de seu ensaio, e os combinamos com breves análises dos haicais de Leminski e das fotos de Pires.

\section{Haicai: um clique de palavras}

Como tudo no Japão, sua prática está profundamente influenciada pela filosofia Zen, essa quase-não-religião, que valoriza o cotidiano e a instantaneidade, a materialidade e a imediatidade da experiência, contra a

\footnotetext{
${ }^{6}$ O crítico de arte Clive Phillpot, ao longo dos anos 1980, reuniu conceitos e definições sobre tipos de livros. Phillpot foi o coordenador do grupo de artigos e, na capa deste exemplar, em vez de uma previsível ilustração, foi impressa a transcriação dos conceitos de livro, livro de arte, livro de artista, arte do livro, livro-obra e livro-objeto (ver Silveira, 2008, p. 45).

${ }^{7}$ Pulicado no livro Ensaios e anseios crípticos (Leminski, 2011), livro que reúne diversos trabalhos de Paulo Leminski. Alguns dispersos, outros feitos sob encomenda para a imprensa, tais trabalhos foram publicados em dois volumes pela Criar Edições. O primeiro volume foi publicado em $1986 \mathrm{e}$ o segundo em 2001. Em 2011, as duas edições foram recompiladas pela Editora da Unicamp em uma edição única, dividida em duas partes. A primeira parte contém os textos em que Leminski acredita ter reunido as noções "teóricas básicas" a partir das quais orientava seus trabalhos, e a segunda parte, como ele mesmo descreve, reúne "textos práticos", voltados à análise de obras realizadas pelo próprio escritor e outros importantes trabalhos de variados autores. Está inserido na primeira parte do livro o ensaio "Click: zen e a arte da fotografia", uma análise introdutória sobre a obra publicada em 1976, Quarenta clics em Curitiba.
} 
pobreza do pensamento conceptual e a tirania do mundo das palavras (Leminski, 2011, p.140-141, grifo nosso).

Poema de origem japonesa, o haicai descende de um processo de adaptação cultural milenar: é a soma do kanji - escrita chinesa, ou ideograma chinês, assumida como própria pelo japonês - à língua japonesa; um misto bem-sucedido que resultou numa vasta produção poética criativa (Franchetti, 2008). Matsuo Bashô, o haijin 8 mais famoso do Japão, reconhecido como o mestre da sucinta forma de escrever poesia, foi quem codificou e estabeleceu os cânones do tradicional haicai japonês. Com mais de três mil discípulos, Bashô "buscou uma síntese. E a obteve. Sob certos aspectos, seu haicai é a fina flor de tudo que de melhor o Extremo Oriente produziu: transcendentalismo hindu, realismo e materialismo chinês, simplicidade japonesa" (Leminski, 1983, p. 28-29). Sua escola ficou conhecida por Escola de Bashô ou Shomôn (Bashô + mon). O haicai de Bashô é concebido com o máximo de concisão e simplicidade. Como estrutura métrica, trata-se de "um poema de dezessete sílabas, com três versos; o primeiro e o terceiro, com cinco sílabas, o do meio com sete" (Leminski, 1983, p. 44). Do ponto de vista semântico, observa-se no primeiro verso a "circunstância eterna, absoluta, cósmica, não humana, normalmente, uma alusão à estação do ano, presente em todo haicai" (Leminski, 1983, p. 44). No segundo verso, "a ocorrência do evento, o acaso da acontecência, a mudança, a variante, o acidente casual" (Leminski, 1983 , p. 45). No terceiro, "o resultado da interação entre a ordem imutável do cosmos e o evento" (Leminski, 1983, p. 45).

Como sugere Haroldo de Campos, o haicai relaciona dois elementos básicos dispersos entre os três versos, "um de permanência, a condição geral, como por exemplo a primavera, o fim do outono, o rochedo, etc., outro de transformação, a percepção momentânea" (Campos, 1972, p.57). Bashô, que viveu em peregrinação pelo Japão escrevendo poemas, eleva o haicai à condição do que é chamado de kadô, ou caminho da poesia, que é a "crença na interdependência de todas as coisas da natureza, as grandes e as pequenas" (Guttilla, 2009, p. 8).

$\mathrm{O}$ haicai valoriza o fragmentário e o insignificante, o aparentemente banal e o casual, sempre tentando extrair o máximo de significado do mínimo de material, em ultrasegundos de

${ }^{8}$ Haijin, aquele que escreve haicais, "praticante do haicai" (Guttilla, 2009, p. 9). 
hiperinformação. De imediato, podemos ver em tudo isso os paralelos profundos com a estética fotográfica. Esses traços característicos do haicai podem ser transpostos sem nenhuma dificuldade para a fotografia (Leminski, 2011, p. 140-141, grifo nosso).

Em Quarenta clics, poeta e fotógrafo estão submetidos à captura do instante: "o poeta haicaísta não descreve, mas elabora em um golpe de linguagem o instante, transformando uma experiência em linguagem poética. O fotógrafo captura um instante, ou mesmo, uma experiência e os aprisionam em forma de imagem fotográfica" (Fontanari, 2011, p. 32). O instante é o elemento de união entre fotografia e haicai, em cada prancha e entre as pranchas.

\section{Contatos e coincidências}

Foto, haicai: eclipse do eu, eclipse da retórica. O mundo que o haicai procura captar é um mundo objetivo, o mundo exterior. [...] Será que isso não se aplicaria também à arte fotográfica? Essa abolição do eu está ligada a outra importante característica do haicai: a ausência de retórica. A própria brevidade torna o haicai imune a toda tentativa de ênfase, de adjetivos desnecessários, de redundância, de entropia. É uma unidade de informação quase pura (Leminski, 2011, p. 141-142, grifo nosso).

No fotolivro, o inconfundível tom de coloquialidade da fotografia de Jack Pires - em que os eventos são tratados com notável preocupação técnica na construção da sintaxe visual, composição de luz, planos, e jogo de sombras - provoca o "satori" haicaístico (Barthes, 1984).

Para Fontanari (2011, p. 32), "há, tanto no haicai quanto na foto, uma brevidade, no sentido de que tudo está posto no horizonte apresentado, nada em abismo e, por isso, não é preciso interpretação, em oposição à poesia ocidental ou à pintura. Essas formas de arte, ou sistemas semióticos, (haicai e fotografia) são objetos onde a linguagem cessa, a consciência cala e solta só um grito: é isso!".

\section{Click: zen e a arte da fotografia}

Como pode haver tanta afinidade entre uma velha forma da poesia japonesa e a mais jovem das artes? Os parentescos íntimos entre o haicai e a fotografia me intrigam, desde que, por voltas de 
1965, comecei a me interessar por essa estrutura poética mínima que os japoneses praticam há, pelo menos, quatrocentos anos. [...] A certeza desse parentesco me levou a realizar o Quarenta clics em Curitiba, com fotos de Jack Pires, mais poemas breves, álbum editado em 1976, em Curitiba, numa caixa com pranchas soltas, uma foto, um haicai (Leminski, 2011, p. 139, grifo nosso).

Há, na citação acima, a definição de uma complexa e preliminar agenda de investigação: "os parentescos íntimos entre o haicai e a fotografia", que intrigaram o autor de Quarenta clics, podem ser explorados em muitos níveis de descrição. Uma análise dos procedimentos usados para explicar o "acoplamento" entre fotos e haicais é apenas parte dessa agenda. Como quarenta fotografias foram "acopladas" a quarenta haicais? Para Barthes, em suas reflexões sobre a ontologia de tais processos, "a forma de arte que permite conceber o haikai = [é] a fotografia" (Barthes, 2005, p. 144). Num diálogo entre Bashô e o monge Bucchô, o haicai é descrito como o instante capturado por escrito, o momento espontâneo colocado em três sucintos versos: "Bashô - Haikai é apenas o que está acontecendo aqui e agora. Então Bucchô compreendeu - Santa pessoa, esse Matsuo Bashô" (Leminski, 1983, p. 22).

No Quarenta clics, as pranchas funcionam como "recortes" intermidiáticos do cotidiano. Baseados em cenas triviais, os haicais representam instantes - refeições servidas em horários fixos e em lugares tradicionais da cidade, frutas amadurecendo depois de colhidas, pássaros mantidos presos em gaiolas, a hora do café...

$\mathrm{Na}$ prancha a seguir (figura 2), foto e haicai capturam um desses instantes, trivial e tipicamente citadino: uma senhora de pé, um balcão ou banca de jornais, um jovem sentado ao lado. Haicai e foto comportam-se como índices de coincidências tempo-espaciais, de acontecimentos aparentemente independentes e sem importância. O noema fotográfico barthesiano acoplado ao haicai de fim de expediente ("seis horas"). Tal instantaneidade indexical, do qual nascem haicai e fotografia, é o que Bashô, traduzido por Leminski, afirma de sua poesia: "haikai é apenas o que está acontecendo aqui-eagora" (Leminski, 1983, p. 22). 


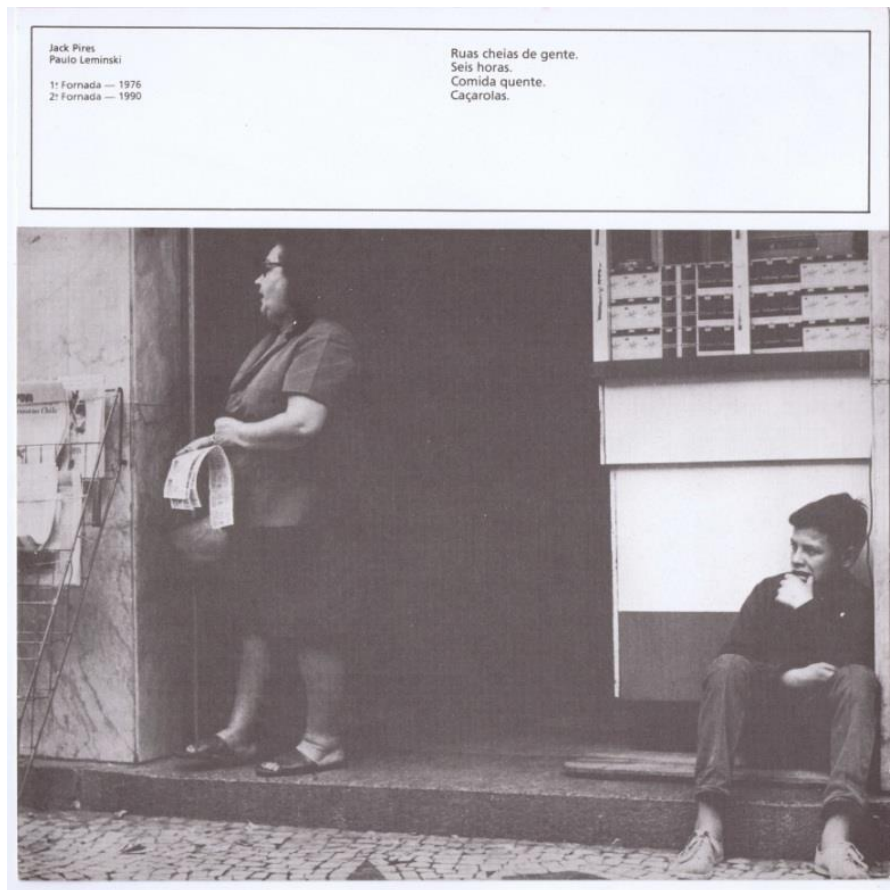

Figura 2 - Reprodução da prancha com o haicai: ruas cheias de gente. / Seis horas. / Comida quente. / Caçarolas (Leminski e Pires, 1990).

\section{O zen de Bresson}

Nesse quadro de parentescos, alguém poderia objetar: mas há uma diferença, uma foto é feita com uma máquina, um haicai, não. Ledo engano. O haicai é também feito através de uma máquina, sua estrutura formal. O que é um esquema formal senão uma máquina mental? (Leminski, 2011, p. 143, grifo nosso).

Para Leminski, o haicai pode ser descrito como um artefato, uma "máquina mental", e como uma experiência de simplicidade sensorial. O poeta encontra no haicai um esquema formal e estético-filosófico para suas criações. Sua experimentação surge da combinação entre o zen e o rigor técnico defendido por Haroldo de Campos (1972). O haicai deve "possuir a concisão, a condensação, a intuição e a emoção - concepções geradas pela inspiração no zen-budismo" (Goga, 1988, p. 37), além de 
técnica e artesania construtiva. Leminski adere à filosofia zen-budista e torna o haicai uma prática para a obtenção do satori, ${ }^{9}$ ao mesmo tempo que incorpora as vanguardas, incluindo o concretismo, a contracultura dos anos 1960 e o tropicalismo.

Ainda sobre as implicações que derivam da afinidade haicaifotografia, o poema, como uma máquina mental, torna-se "uma espécie de objetiva portátil, apta a captar a realidade circunstante e o mundo interior, e a convertê-los em matéria visível" (Campos, 1972, p. 65).

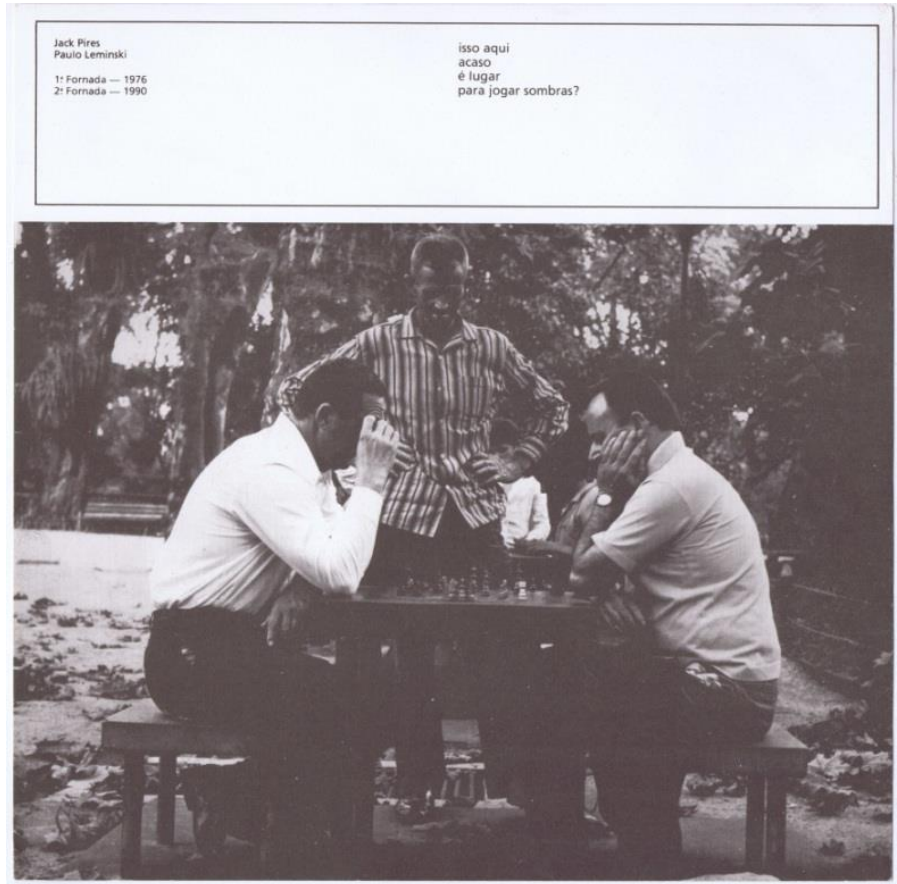

Figura 3 - Reprodução da prancha com o haicai: isso aqui / acaso / é lugar / para jogar sombras? (Leminski e Pires, 1990).

Na prancha reproduzida na figura 3, é notável o "acoplamento" dos sistemas. A imagem está organizada de acordo com um sutil balanço de

\footnotetext{
${ }^{9}$ Satori é um termo utilizado na filosofia zen para indicar um estado que "é aqui e agora, um instante que é todos os instantes, momento de revelação em que o universo inteiro - e com ele a corrente de temporalidade que o sustenta-se desmorona. Este instante nega o tempo e nos coloca diante da verdade" (Paz, 1976, p. 160).
} 
correspondências sintáticas e de relações entre luzes e sombras. A composição de "claros" e "escuros", tanto no primeiro quanto no segundo planos, encontra-se bastante equilibrada; a mancha gráfica formada pelo senhor de pé divide o quadro ao meio, produz uma duplicação ou espelhamento de cena. O poema, bastante estruturado, especialmente em termos rítmicos, possui um paralelismo sonoro entre o terceiro e quarto versos (/ar/). Intersemioticamente, o haicai atua como uma questão, ou uma indagação, sobre as qualidades da fotografia, em uma descrição quase direta da cena, um exemplo de metalinguagem enfatizada pela interrogação ao fim do haicai.

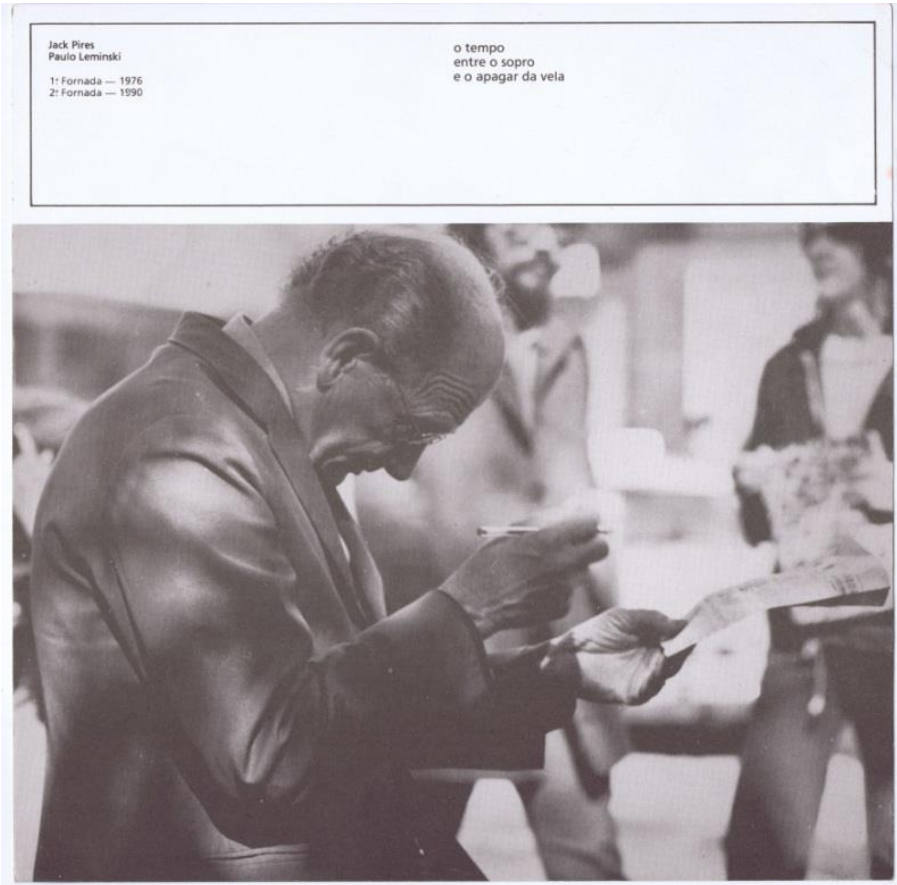

Figura 4 - Reprodução da prancha com o haicai: o tempo / entre o sopro / e o apagar da vela (Leminski e Pires, 1990).

Na prancha da figura 4, o resultado também é bastante estruturado em termos de composição sintática visual. Há um sutil balanço entre claros e escuros e algum equilíbrio entre os eventos estabelecidos no primeiro e segundo planos. O haicai, sobre o intervalo temporal de uma 
ação, a ocorrência de um evento, possui diversos paralelismos sonoros formando rimas internas assonantes, com alta incidência dos mesmos apoios vocálicos (/e/ /o/, /e/ /a/). É também notável como poema e fotografia atuam intersemioticamente - o instante bressoniano de uma captura fotográfica precisa representado no intervalo temporal de um evento singular.

\section{Uma vez, um gesto}

Entre os mestres de haicai, sempre foi enfatizada essa imediatidade irrepetível e incorrigível. O verdadeiro haicai é aquele que desponta de súbito, inteiro, íntegro, sólido objeto do mundo, num momento decisivo que não depende da vontade, do arbítrio do poeta. Como o ato de bater uma foto. [...] O que é irrepetível não pode ser traduzido, vertido, passado para outro sistema de signos. Fotos e haicais são ícones: ícones são coisas, coisas não tem tradução (Leminski, 2011, p. 142, grifo nosso).

Em nossa abordagem, os processos são icônicos e indexicais. Isoladamente tratados, haicai e fotografia representam seus objetos em relações semioticamente descritas como icônicas e indexicais, de um lado, e estão "acoplados" através de relações da mesma natureza, de outro. $\mathrm{O}$ fundador do pragmatismo, C. S. Peirce (ver Bergman e Queiroz, 2014), descreve o índice como dependente de conexões tempo-espaciais entre signo e objeto - "um índice é um signo que se refere ao objeto que denota em virtude de ser realmente afetado por este objeto" (Peirce, 1931-1958, v. 2, parágrafo 248). A noção de covariação é corrente em suas explicações. Diversas relações satisfazem essa noção. De um pronome demonstrativo, que "força atenção para um objeto particular, sem descrevê-lo" (Peirce, 1931-1958, v. 1, parágrafo 369), a um sintoma físico. São também exemplos: termômetros (covariação entre a altura da coluna de mercúrio e temperatura), hidrômetros (Peirce, 1931-1958, v. 5, parágrafo 73), barômetros, balão de vento (covariação da posição do balão e a direção do vento). $\mathrm{O}$ índice tem dois componentes principais, contiguidade física e direcionamento da atenção (Atkin, 2005). O primeiro está relacionado a uma atuação causal - fumaça é índice de fogo e também seu efeito causal. O segundo está relacionado à indicação de um item particular, sem desenvolvimento no tempo, como uma seta ou um dedo apontado diretamente para algo. Outra característica é que o índice não afirma ou 
caracteriza o objeto, ele apenas indica sua existência. Ambos, haicai e fotografia, são índices dos instantes capturados, mas também são análogos dos objetos representados. Ícones são signos que se baseiam em relações de similaridade (Peirce, 1931-1958, v. 2, parágrafo 276), ou de analogia (Peirce, 1931-1958, v. 1, parágrafo 369), que podem prescindir de qualquer correlação tempo-espacial que um signo pode ter com um objeto existente (Peirce, 1931-1958, v. 5, parágrafo 73). Se um signo é um ícone de seu objeto, ele compartilha certas propriedades ou qualidades que seu objeto possui (Queiroz, 2010).

Pode-se perguntar: como estão semioticamente relacionados haicai e fotografia no Quarenta clics? Os haicais de Leminski encontram similitude e vínculo formal nas fotografias de Pires. Esta propriedade icônica aparece sob diversas formas, com ênfase em analogias estruturais e qualitativas entre os fenômenos relacionados. Entre as analogias estruturais, pode-se mencionar: distribuição rítmica de diversos componentes, sonoros (haicai) e gráficos (foto), além do balanço sintático de paralelismos visuais e verbais. Assim, diversos elementos da fotografia de Pires e da poesia de Leminski estão de tal forma relacionados que a palavra bem como certas propriedades paralinguísticas podem ser interpretadas como análogas a diversas propriedades da fotografia, em diversos níveis de organização (rítmico, semântico, morfológico, etc.). Haicais e fotografias são índices de eventos e também ícones um do outro.

\section{Considerações finais}

Passados 40 anos de sua realização, Quarenta clics em Curitiba permanece negligenciado e praticamente desconhecido. Isso é surpreendente, diante do reconhecimento de Leminski como um dos mais importantes escritores brasileiros da segunda metade do século $X X$, devido a sua projeção como poeta e prosador, pela apropriação crítica e criativa de sua obra por músicos e artistas visuais. Não há qualquer trabalho sistemático sobre seu único exemplo de fotolivro. Mesmo entre trabalhos ocasionais, são poucos aqueles destinados a discutir de forma rigorosa Quarenta clics em Curitiba ou a reconhecê-lo como a publicação que inaugurou a prática haicaística de Leminski.

Podemos afirmar que o exercício intermidiático de Leminski e Pires, "descendentes" de Bashô e de Bresson, consistiu em experimentar a relação potencialmente "natural" dos sistemas e processos acoplados 
(haicai e fotografia). No Quarenta clics, a trivialidade precisa dos haicais de Leminski potencializa-se na relação com a fotografia bressoniana de Pires. Relacionados, haicai e fotografia capturam o instante "coloquial, livre e desimpedido", como Paz (1976, p. 159) caracteriza o haicai. Os experimentos de Leminski e Pires, a relação entre os procedimentos aprendidos com a tradição de Bashô e que envolvem a compressão do instante percebido e materializado em um rigoroso esquema formal, combinados à captura fotográfica precisa do evento singular em Curitiba, fazem de Quarenta clics um dos mais notáveis exemplos da história do fotolivro de literatura brasileira.

\section{Referências}

ATKIN, Albert (2005). Peirce on the index and indexical reference. Transactions of the Charles S. Peirce Society, Bloomington, v. 1, n. 41, p. 161-188.

BARTHES, Roland (1984). A câmara clara. Rio de Janeiro. Nova Fronteira.

BARTHES, Roland (2005). A preparação do romance São Paulo. Martins Fontes, v. I.

BERGMAN, Mats; QUEIROZ, João (Org.). (2014). The Commens encyclopedia: the digital encyclopedia of Peirce studies. On-line. Disponível em: http:/ / www.commens.org/encyclopedia. Acesso em: 16 maio 2016.

CAMPOS, Haroldo de (1972). A arte no horizonte do provável. São Paulo: Perspectiva. FERNÁNDEZ, Horacio (2011). Fotolivros latino-americanos. São Paulo. Cosac Naify.

FONSECA, Pedro Carlos Louzada; SOUSA, Fábio D’Abadia de (2008). Literatura e fotografia: o anseio pela apreensão do instante. Signótica, Goiânia, v. 20, n. 1, p. 149-174, jan./jun.

FONTANARI, Rodrigo (2011). Marshall Mcluhan e Roland Barthes diante da Fotografia e do Haicai. Entretextos, Londrina, v. 11, n. 2, p. 28-45, jul./dez.

FRANCHETTI, Paulo (2008). O haicai no Brasil. Alea: Estudos Neolatinos, Rio de Janeiro, v. 10, n. 2, p. 256-269, jul./dez.

GOGA, Hidekazu Masuda (1988). O haicai no Brasil. Tradução: José Yamashiro. São Paulo. Oriento.

GUTTILLA, Rodolfo (2009). Boa companhia: haicai. São Paulo. Companhia das letras. LEMINSKI, Paulo (1983). Bashô. São Paulo. Brasiliense.

LEMINSKI, Paulo (2011). Ensaios e anseios crípticos. 2 ed. ampl. São Paulo. Unicamp. 
LEMINSKI, Paulo; PIRES, Jack (1990). Quarenta clics em Curitiba. Curitiba. Etecetera. MICHELI, Mario de (2008). As vanguardas artísticas. São Paulo: Martins Fontes.

NOVAIS, Carlos Augusto (2008). As trapaças de Occam: montagem, palavravalise e alegoria no Catatau, de Paulo Leminski. Tese (Doutorado em Literatura Brasileira) - Universidade Federal de Minas Gerais, Belo Horizonte.

PAZ, Octavio (1976). Signos em rotação. São Paulo. Perspectiva.

PEIRCE, Charles. S. (1931-1958). The collected papers of Charles Sanders Peirce. Edited by C. Hartshorne, P. Weiss and A. W. Burks. Cambridge: Harvard University Press, 8 v. Electronic edition.

QUEIROZ, João (2010). Tradução criativa, diagrama e cálculo icônico. Alea: Estudos Neolatinos, Rio de Janeiro, v. 12, n. 2, p. 322-332.

SHANNON, Elizabeth (2010). The rise of the photobook in the twenty first century. St Andrews Journal of Art History and Museum Studies, St Andrews, v. 14, p. 55-61.

SILVA, Vittor Ibañes da (2013). Fotografia, literatura e surrealismo: uma análise das relações entre fotografia e literatura na obra Nadja, de André Breton. Monografia (Graduação em Letras) - Universidade de Brasília, Brasília.

SILVEIRA, Paulo Antonio de Menezes Pereira da (2008). As existências da narrativa no livro de artista. Tese (Doutorado em Artes Visuais) - Universidade federal do Rio Grande do Sul, Porto Alegre.

Recebido em 22 de agosto de 2016.

Aprovado em 17 de novembro de 2016.

\section{resumo/abstract/resumen}

\section{Quarenta anos do fotolivro Quarenta clics em Curitiba, de Leminski e Pires}

Ana Luiza Fernandes

João Queiroz

Quarenta clics em Curitiba, publicado em 1976, é um raro, quase sem precedentes, exemplo de fotolivro de literatura brasileira. Realizado colaborativamente por Paulo Leminski e Jack Pires, o exemplar não aparece em qualquer antologia dedicada ao gênero "fotolivro", nem é mencionado como projeto de livro de artista (artistic book) em publicações especializadas, sendo ainda negligenciado 
pela crítica e historiografia literárias. Na obra de Leminski, considerado um dos mais criativos e importantes escritores brasileiros da segunda metade do século $\mathrm{XX}$, trata-se de seu único experimento intermidiático e sua primeira publicação como haicaísta. Neste artigo, introduzimos Quarenta clics em Curitiba, combinando algumas de suas pranchas com fragmentos de Click: zen e a arte da fotografia, único ensaio em que Leminski descreve as diversas fases de concepção do fotolivro.

Palavras-chave: Quarenta clics em Curitiba, Paulo Leminski, fotolivro de literatura, haicai.

\section{Forty years of the photobook Quarenta clics em Curitiba, by Leminski e Pires}

Ana Luiza Fernandes
João Queiroz

Quarenta clics em Curitiba, published in 1976, is a rare, almost unprecedented example of a Brazilian literary photobook. Conceived collaboratively by Paulo Leminski and Jack Pires, the work does not appear in any anthology dedicated to the "photobook" genre. Neither is it mentioned as an artist book project in specialized publications. It is, in sum, neglected by literary criticism and by historiography. This is Leminski's sole inter-mediatic experiment and the author's first haiku publication. In this paper, we introduce Quarenta clics em Curitiba, alternating excerpts from this work with fragments from Click: Zen e a Arte da Fotografia, an essay in which Leminski, who is considered one of the most creative and important Brazilian writers of the second half of the twentieth century, describes the various stages of this photobook project.

Keywords: Quarenta clics em Curitiba, Paulo Leminski, literature photobook, haiku.

\section{Cuarenta años del fotolibro Quarenta clics em Curitiba, de Leminski e Pires}

Ana Luiza Fernandes

João Queiroz

Quarenta clics em Curitiba, publicado en 1976, es un raro ejemplo, casi sin precedentes, de fotolibro en la literatura brasileña. Una colaboración de Paulo Leminski y Jack Pires, la obra no aparece en ninguna antología dedicada al género "fotolibro", ni es mencionada como un proyecto de libro de artista (artistic book) en publicaciones especializadas, siendo así olvidada por la crítica y la historiografía literaria. La obra de Leminski, considerado uno de los escritores brasileños más creativos e importantes de la segunda mitad del siglo XX, es su 
único experimento intermediático y su primera publicación como escritor de haikús. En este trabajo, introducimos Quarenta clics em Curitiba, interpolando este trabajo con fragmentos de Click: Zen e a Arte da Fotografia, el único ensayo en que Leminski describe las diferentes etapas de diseño del fotolibro.

Palabras clave: Quarenta clics em Curitiba, Paulo Leminski, fotolibro de la literatura, haikú. 